This is a preprint of: Ilagan, K.A. \& Soriano, C.R. (2019). Data Journalism in the Philippines: New trends, new practices for old media organizations. In B. Mutsvairo, S. Bebawi, \& E. Borges-Rey, Data Journalism in the Global South: Comparative Perspectives (pp. 125-143). Palgrave Macmillan https://www.palgrave.com/gp/book/9783030251765

\title{
Data Journalism in the Philippines: New trends, new practices for old media organizations
}

\author{
Karol Anne Ilagan ${ }^{1}$ and Cheryll Ruth Soriano ${ }^{2}$
}

With the continuous emergence of data-driven journalistic content and working methods in newsrooms around the world (Appelgren and Nygren, 2014; Parasie 2015; Knight 2015; Charbonneaux and Gkouskou-Giannakou, 2015), data journalism has come to be a significant topic of concern among practitioners and researchers alike, even as much of the research has focused on the experiences of Northern America and Europe (Lesage and Hackett, 2013). Assumed to strengthen "journalistic objectivity", provide new tools to news organizations to sustain government accountability", provide new ways of telling evidence-based stories, and encourage citizens' "political participation” (Parasie and Dagiral, 2013) news organizations globally, as well as in the Philippines, are deploying data journalism in their practices. This is evidenced by the work being done by the Philippine Center for Investigative Journalism (PCIJ) and Rappler in its investigations and data projects and the Philippine Daily Inquirer (Inquirer), ABS-CBN News, and GMA News with its data stories, special reports, interactives, and visualizations. Smaller news organizations have also started to join, launching their data journalism initiatives. The adoption of data journalism include presenting news as structured

\footnotetext{
1 Philippine Center for Investigative Journalism \& Professional Lecturer, Department of Communication, De La Salle University Manila. Email: karol.ilagan@dlsu.edu.ph

${ }^{2}$ Professor, Department of Communication, De La Salle University Manila. Email: cheryll.soriano@dlsu.edu.ph
} 
information through regular incorporation of databases in news stories, the subsequent designing of research tools that will encourage readers to actively engage with data, and reducing the dependence on government agendas by constantly updating databases that allow ordinary citizens to monitor the decisions of city officials and other government bodies (Parasie and Dagiral, 2013). Changes are reflected not only on the presentation of stories but also on organizational practices, norms, and values while also posing challenges to organizational resources.

It has been assumed that news organizations in the Philippines practice data journalism in its most elemental form, i.e., treating data as a source to be gathered and validated and applying statistics to interrogate it and visualizations to present it (Howard, 2014). Interestingly, this practice of "elementary data journalism" runs in parallel with factors that create an environment for data journalism to thrive. These include, among others, the availability and accessibility of data, level of data literacy in newsrooms, access to journalistic technologies, and resources dedicated by a news organization for data work. Yet, there is paucity of analysis of the experiences of local news organizations that look into the realities of practice amidst technological possibilities.

With these premises in mind, this chapter provides an exploratory analysis of data journalism experiences of four of the most established and largest news organizations in the Philippines. The research examines how these local news organizations adopted data journalism into their traditional practice beginning in the 1990s when use of the internet likewise started. This chapter tracks the development of data journalism in the Philippines by analyzing: 1) key organizational changes that needed to be made in the move towards a more data-driven approach in reporting; 2) adjustments in the story identification, research, collaboration, analysis, and 
presentation of stories as well as challenges encountered; and, 3) emerging good practices as well as areas for strengthening organizational capacity and institutional and legal hindrances that pose challenges for data journalism to thrive locally.

\section{Organizational Changes and Challenges with Data Journalism}

A rather unequal landscape characterizes data journalism. Whereas resource-rich newsrooms are able to maximize the potentials of data journalism, newsrooms with limited budget struggle to carry out data-driven projects due to the lack of access towards new journalistic tools and processes (Fink and Anderson, 2015). This notwithstanding, extant literature has shown that for large or small organizations, organizational transformations are faced with the adoption of data journalism. This section discusses some of these interconnected changes and challenges in: (1) organizational values, objectives, and structures; (2) organizational resources; (3) research and storytelling techniques; and (4) strategies for audience engagement .

\section{Changes in journalistic values and objectives}

Though not an explicit exploration of data journalism, Tandoc's ethnographic account of the extent in which web-analytics are integrated in the news work of leading online newsrooms in the U.S. showed that the decision of some newsrooms to adopt data-driven practices shape journalistic values and objectives $(2014$, p.13). More than just marginally considering readership in the production of news, the study reveals that audience engagement with online news content which are quantified as "web traffic" (Tandoc, 2014, p.2) can also end up becoming the most defining, if not the only, factor that online and data journalists take into account when coming up with news. On the contrary, Borges-Rey's (2016) study found that journalists see data as offering a "wider range of sources" that can help them "expose corporate wrongdoings" and hold "private 
institutions under similar degrees of scrutiny" (p.836). Despite the disruptive effect on traditional journalistic standards, the study demonstrates the enduring value of "journalistic reflexivity" in news production that drives data journalism (Borges-Rey, 2016, p.838). Remarkably, the study also provides evidence on the ways in which regional and smaller newsrooms can work their way around their resource limitations by adopting the same collaborative ideals of open source movements. Informants in the study report of frequent collaboration with "civic organizations", "open-source initiatives", as well as "communities of programmers", "libraries, trusts, and foundations" (Borges-Rey, 2016, p.840).

\section{Research and dealing with data}

Lesage and Hackett's (2013) analysis of data journalism identifies a judicious set of challenges for two of the key selling points of data journalism - openness and objectivity, that shape changes in how news organizations conducted research and dealt with data. Data journalism represents a shift to a type of credibility now judged based on the openness of data with openness referring to its accessibility in terms of format and visualization - and an objectivity that is automatically granted because data is believed to be objective in itself. However, Lesage and Hackett (2013) caution against taking for granted the openness and objectivity of data. For one, raw data often requires filtering and cleaning so that it may become understandable, machine-processible, and accessible to readers (Lesage and Hackett, 2013, p.42), which poses a challenge in terms of organizational resources needed to support operations. Moreover, they warn of the possibility of data being contaminated or tampered with datasets that are incomplete, inaccurate, or even falsified (2013, p.45; Parasie, 2015). Seen in this light, preserving the "facticity of data" in data journalism would require some tremendous organizational adjustments. 
Through a systematic review of the visual design of data journalistic outputs by the New York Times, the Guardian, the Financial Times, the Washington Post, and Slate, Segel and Heer (2011, p. 5) comment on the subsequent failure of online journalists to achieve effective "narrative communication" using visualized data. This appears parallel with the challenges posed by Knight's (2015) content analysis of data journalistic content in UK national daily and Sunday newspapers about how data journalistic methods are used by organizations for its visual appeal at the expense of clarity, leading to outputs that are "largely superficial, institutionally sourced and non-remarkable" (2015, p.70).

\section{Changes in organizational structures and challenges to resources}

Newsrooms, whether rich in resources or otherwise, have begun to integrate data-driven practices and approaches to journalism on a structural level. This is shown through the creation of new editorial departments that are specifically tasked to produce data-driven content, the occasional enlistment of data-oriented journalists or programmers within already-existing departments, and the self-driven initiative of journalists to learn new skills that enable them to engage with data to keep up with the times (Royal, 2012; Parasie and Dagiral, 2013; Borges-Rey, 2016; Applegren and Nygren, 2014; Fink and Anderson, 2015). In some cases, news companies that are struggling to survive amid the increasingly digitized nature of news consumption have resorted to laying off throngs of its veteran employees, all the while cultivating its pool of webspecializing practitioners (Tandoc, 2014).

The collective understanding of this new journalistic practice remains at the developmental level and would require further explorations that not only take into account the diverse nature of newsroom cultures as well as "consider the political, cultural, technological, and economical factors that influence the "sociology of news" (Ausserhoffer et al., 2017, p.2). 
Economic resource remains central in enabling newsrooms to integrate data journalism in their organizations, which substantiates the idea that data journalism is plagued by issues of inequity. This makes notable the seemingly harmonious intersection between traditional journalistic principles with the promising new capacities of data and computing methods. We now turn to the data journalism experiences of Philippine news organizations.

\section{Data journalism: The Philippine case}

The study focuses on four of the most established and oldest news organizations in the Philippines: ABS-CBN Corp. (ABS-CBN) GMA Network Inc. (GMA), the Philippine Center for Investigative Journalism (PCIJ), and the Philippine Daily Inquirer (Inquirer). Among the major sources of news and investigations in the country, GMA and ABS-CBN have been operating for at least 50 years (established in 1950 and 1957, respectively) although their operations ceased or were controlled by government when the Philippines was placed under Martial rule in 1972. Until now, the two are considered the largest broadcast and online news organizations in the country. Although Inquirer and PCIJ were established only in the 1980s, they were selected as case studies because they are among the country's oldest print news outlets and investigative nonprofits, respectively. The four news organizations were also chosen in order to be able to capture experiences across print, online, and broadcast media. Through depth interviews with senior journalists at ABS-CBN, GMA, PCIJ, and Inquirer as well as documentary research, we surface insights on the changes and challenges experienced by news organizations located in the global South as they embrace data journalism. Each representative was asked to answer a similar set of questions pertaining to the organization's use of data in reporting, among others. We first provide a brief background on the four organizations and the media environment in the Philippines then proceed with their respective experiences. 
$\boldsymbol{A B S}-\boldsymbol{C B N}$ is the biggest media conglomerate in the Philippines, offering diverse programs from entertainment to news and current affairs. ABS-CBN's flagship TV station ABSCBN 2, radio station DZMM 630, and online news portal ABS-CBN News dominate the media market with the highest audience share (Reporters Without Borders \& Vera Files, 2016).

Media giant $\boldsymbol{G M A}$ is another commercial television and radio network in the Philippines. Next to ABS-CBN, GMA takes a significant share of the media market with its flagship TV station GMA 7, radio station DZBB 594, and news website GMA News Online.

The PCIJ is an independent nonprofit that specializes in investigative reporting. It was founded in 1989 by nine Filipino journalists who realized, from their years on the beat and at the news desk, the need for the news media to go beyond day-to-day reportage. PCIJ publishes www.pcij.org for its investigations; www.pcij.org/blog, an institutional news and analysis blog; and www.moneypolitics.pcij.org, a citizen's research tool on elections, public funds, and governance in the Philippines.

Founded in 1985, the Inquirer is one of the most widely read broadsheets in the country. Inquirer offers daily news and features in print and online via www.inquirer.net. Inquirer is part of the Inquirer Group, which also publishes the tabloids Bandera, Inquirer Libre, and Cebu Daily News.

\section{The state of the Philippine press}

Because of the strong protections to free speech and free press promulgated by the Philippine Constitution, the Philippines is considered to have one of the freest and most rambunctious media in Asia. The Bill of Rights provides for the citizens' right to information. Republic Act No. 53 of 1946, also known as the "Shield Law" protects journalists from having to 
reveal their sources ${ }^{3}$. Jurisprudence has for the most part upheld four aspects of press freedom, notably freedom of prior restraint, freedom from subsequent punishment, freedom to publish and broadcast, and freedom of access to information (Friedrich Ebert Stiftung, 2011). Compared to other Asian countries under restrictive regimes, the Philippine press fairly enjoys a certain level of freedom that has allowed media outlets like ABS-CBN, GMA, PCIJ, and Inquirer to experiment and embark on new ways of telling stories such as the use of data in reporting. Yet, despite constitutional and legal guarantees, media freedom in practice is stifled by various legal, political, and economic factors. Media violence, which has been well-documented, also pose real challenges to media practitioners (Brooten, 2011; Coronel, 2018).

For instance, Freedom House in its Freedom of the Press reports of the recent years has categorized the media in the Philippines as "partly free," with the latest round of the report finding that news organizations in the country offer a wide range of views and cover controversial topics but journalists are compromised by the threat of legal action such as criminal defamation laws. Politically motivated libel cases and the threat of violence have also caused some journalists and media outlets to practice self-censorship (Freedom House, 2017). Further, the Committee to Protect Journalists tagged the Philippines as "one of the deadliest places in the world for journalists" (Agence France-Presse, 2016). The killing of 32 journalists and media workers in Ampatuan town in November 2009 shows how local warlords can silence any kind of reporting that goes against their political or economic interests (Friedrich Ebert Stiftung, 2011).

More recently, President Rodrigo Duterte has turned up the pressure on media organizations critical of his administration (Coronel, 2018). Shortly after winning the May 2016 elections, the President said that "corrupt" journalists "are not exempted from assassination"

\footnotetext{
${ }^{3}$ Amendments to expand this law beyond print publication is pending in the Philippine Senate (Senate of the Philippines, 2017 May)
} 
(Agence France-Presse, 2016). This, according to Freedom House, contributes to a hostile environment that could incite more murders in an already risky nation for reporters. The Philippines was thus included among several democracies where political leaders attack the credibility of the press through hostile rhetoric, personalized abuse online, and indirect editorial pressure. These leaders, the report notes, reject the traditional watchdog role of a free press in democratic societies by delegitimizing critical sources of information and reshaping news coverage to their advantage (Freedom House, 2017).

These threats to press freedom have created a difficult working environment for journalists in the Philippines generally, and specifically for data journalism. Access to data can be made more difficult due to certain controls imposed by political force (a theme that will be discussed further in a later section), organizations may be threatened upon reporting important but potentially damaging data; and published data can be used and manipulated to obtain new meanings. How these threats and difficulties are felt largely differ by organization, the kind of reporting they do, and the political context wherein the media outlet operates. News organizations in the Philippines, like the four media outlets in this study, generally thrive in this dissonant working environment well-aware of both opportunities and challenges.

\section{The use of data and broad changes in organizational structures}

Except for PCIJ which has had a data research team as core part of the organization, all three mainstream media outlets have recognized over the years the need for a unit dedicated to the research and data requirements of their reporting teams. Philippine Daily Inquirer's Inquirer Research was created in the 1990s, starting with one researcher until it became a full-fledged department. Inquirer Research Head shared that the team, now composed of six staff members, 
acts as "data fillers" in charge of providing supplemental facts in a news report in addition to fact-checking stories (Personal communication, December 11, 2018). Created with a similar purpose, GMA News Research was formed in 2003 to provide "value-added" content for the network's news programs that can give depth and context to a news story. TV journalism, which is GMA's focus, deals more with news events, but GMA's News Research Manager explained that the team has been making a conscious effort to explain the news a little further, going beyond the five Ws and one $\mathrm{H}$ (Personal communication, November 28, 2018). The team now works closely with newscasts, particularly GMA News' flagship news program 24 Oras, to ensure that its research requirements are served. They also provide content support to the morning and evening newscasts of both GMA 7 and GMA News TV, in addition to attending to the needs of GMA News Online and various public affairs programs. In 2015, ABS-CBN also formed the ABS-CBN Investigative and Research Group which is also meant to serve the research needs of various programs across the network's platforms. According to its Research Head, the network's programs have their own teams in charge of the research per episode or story, but management saw the need for a dedicated unit that will conduct strategic research, such as providing additional data for context in reports, building databases for internal use, and keeping an archive of records gathered in the course of producing stories (Personal communication, January 21, 2019).

Archiving is central to the formation of the research teams of Inquirer, GMA, and ABSCBN, but being able to work with data closely has also allowed each unit to produce their own editorial outputs, including data-driven investigations, features and infographics. Inquirer Research, for instance, produces sidebars that accompany the big stories. These come in the form of backgrounders, chronological summaries, or an expanded version of the five Ws and one H. 
The sidebars are "mini data journalism at work" as they are sourced from various documents or databases. Inquirer used to produce comprehensive briefings about the most important current issues. Edited by one of its top columnists, this full-page, data-driven output was composed of explanatory reports supplemented by data visualizations.

GMA News Research started from scratch and has slowly built its databases over the years. But from merely providing background data, the team has transitioned into producing their own special reports for news programs and GMA News Online. On top of content support, the research team also work on their own story or database projects. The team lead explained that remarkable stories emerge from sifting through datasets so they also pitch and produce stories for the news programs or the network's online news site.

The ABS-CBN Investigative and Research Group also provides research support to the network's programs in addition to producing their own stories. A story being produced could trigger the need for certain data that the group will be asked to provide or a dataset itself may serve as the source of stories. The team considers its historical databases as their key contribution given that reporters might not have enough time to gather comprehensive data given their daily deadlines. ABS-CBN's research group also recently formed a Data Analytics Team, which takes advantage of available data that need not be requested or reworked heavily for analysis. Headed by an economist, the team takes advantage of economic and other data available online to help explain trends and patterns in the economy such as inflation, trade, and the like. Titled Dissecting Data, these data-driven features are presented in augmented reality format on ANC, TV Patrol, and ABS-CBN News online. Through Dissecting Data, ABS-CBN is able to experiment on new ways of looking at data and render it in a way that will be most useful to readers. The team for 
instance did the "Pinoy Tax Reform Calculator" to help citizens better understand the impact of the new Tax Reform for Acceleration and Inclusion (TRAIN) law on their salary.

Use of data is inherent in PCIJ's practice since its early years. Before computer-assisted reporting or data journalism emerged as a discipline, PCIJ reporters by dint of conducting investigations have almost always used data as source. In practice, investigative journalists gather both supporting and contradictory evidence for a story, then weigh what the evidence shows. Data, along with other types of sources, are collected, structured, and analyzed to either uncover new information and/or independently verify findings. Thus many of PCIJ's groundbreaking stories from the 1990s until today have also been built around databases. In 2000, PCIJ's investigation that helped in providing evidence leading to the impeachment of former President Joseph Estrada was made possible through a paper trail of property and corporate records that established an accumulation of over P2 billion worth of real estate for the former president's wives and children.

\section{Implications of data journalism to changes and demands in organizational resources}

The concept of using data to tell stories is not new to the four news organizations, but the way it has been applied over the years has evolved alongside various factors, i.e., the quality and quantity of data available, data literacy of reporters, and technology, which all demanded organizational resources.

For a non-profit media organization such as PCIJ, collaborations with researchers and grant resources serve as important resource drivers for data journalism initiatives. Since the 1990s, PCIJ, led by its Research Desk (transformed into a Data Desk in 2015) has launched datadriven projects in the form of books, researches, and online data portals. In 2004, PCIJ published 
the book "The Rulemakers: How the Wealthy and Well-Born Dominate Congress," which tells the story of the Philippine legislature and the men and women who make up the body (Coronel, et.al., 2004). "The Rulemakers" built on the work previously done with the Institute for Popular Democracy in "The Ties That Bid," a book published in 1994. The author, who was then using a Lotus computer program, passed on his work to PCIJ together with a searchable CD-ROM containing information on the assets, careers, professions, and other demographic characteristics of legislators which can no longer be included in the book. Since then, PCIJ monitored the composition and activities of Congress and had been for a time publishing online demographic and other information on both the House of Representatives and Senate on the website www.isite.ph (Coronel, et.al., 2014). I-site is no longer active, but it is considered as "one of the first data-driven journalism initiatives in the country" (Oliva, 2013). In 2011, PCIJ started another data journalism project called MoneyPolitics, which was designed as a "resource, research, and analysis tool on elections, public funds, and governance in the Philippines." PCIJ received a three-year grant from the Open Society Foundation to support the acquisition of more documents and networking activities of MoneyPolitics Version 1, which was launched on May 3, 2013, World Press Freedom Day (Philippine Center for Investigative Journalism, 2013). In September 2013, Hivos Foundation, through the Southeast Asia Technology and Transparency Initiative, approved a grant for PCIJ to develop Version 2 of MoneyPolitics. In November 2014, PCIJ launched a 30-month project to organize its database management system starting with the development of MoneyPolitics Version 3. A team of encoders, proofreaders, researchers, and web developers has since been working on the project. PCIJ's three decades' worth of reporting has resulted in an accumulation of records, which it has been putting to good use by embarking on data projects intended to facilitate greater citizen access to data. 
The hiring of staff members with data skills has become a minimum for most of the research teams in the organizations covered in this study. Reporters of PCIJ for instance are expected to be comfortable with data and should ideally be able to imagine and convey how the findings might be best visualized. The same goes for ABS-CBN and GMA whose researchers and even interns are expected to be familiar with data work or at least know the basics of Microsoft Excel. Inquirer's Research team lead also pointed out the importance of having data skills or some knowledge of spreadsheets as a minimum requirement. Trainings are rolled out to get reporters more comfortable with numbers and understand the work embedded within the different stages of producing a data-driven.

\section{Working with databases: getting, cleaning, analyzing, and presenting data}

Building databases from scratch has become a norm for all four media outlets. To develop its databases, the techniques and technologies ABS-CBN, GMA, PCIJ, and Inquirer employ include public-records requests and web scraping tools to obtain data, spreadsheets like Microsoft Excel and relational database software such as MySQL to clean and analyze data, and mapping and visualization applications to present data. The practice, although tedious and timeconsuming, has opened possibilities for allowing reporters to explore data more freely, build even larger and more nuanced datasets, make comparisons across time and geographical areas, and even question government data itself. Reporting is enhanced when one is able to look at the bird's eye view and see patterns and trends, while also getting to the granular level by scrutinizing specific incidents and detecting outliers. Identifying case studies from the large data set likewise helps humanize data. Notably, however, there appears limited collaboration amongst news organizations covered in this study in terms of sharing databases or cross-referencing data. 
The media coverage of President Rodrigo R. Duterte's "war on drugs" for instance is writ large in data. Since the anti-drug campaign started in 2016, Inquirer and ABS-CBN have independently monitored the killings in an attempt to document details of the death toll that the police could not openly and regularly provide. Largely sourced from news reports and releases from government agencies, Inquirer's “The Kill List” (Philippine Daily Inquirer, July 7, 2016) and ABS-CBN's catalog recorded drug-related fatalities and the manner by which each victim was killed (ABS-CBN, July 13, 2016). The dataset then became basis for stories like ABSCBN's six-part series on the unheard stories of some 50 men killed in police operations through the accounts of witnesses, their families, and neighbors. (Only ABS-CBN's list is online and updated as of this writing). PCIJ meanwhile looked into the police's official death counts, raising issues about the law enforcement's constantly changing concepts and terms as well as the ambiguous (and often contradicting) cumulative number of deaths.. Media monitor Center for Media Freedom and Responsibility or CMFR commended these news organizations for their initiative to map and track the killings of suspected criminals and to give readers an insight into the victims' lives, presenting the human dimension of the anti-drug campaign (Center for Media Freedom and Responsibility, 2018).

\section{Legal and other challenges}

Parallel to these data-driven efforts are the often-frustrating experiences of journalists in obtaining government records across different administrations. What has remained constant through the years is the difficulty and inconsistency characterizing public-record access primarily because of the absence of a working Freedom of Information law. Although the FOI law has been in legislative limbo for several decades now, a battery of other laws and orders support access to state records. The Duterte administration's issuance of the FOI Executive 
Order for example may be seen as a welcome development, but our interviews show that this also created more difficulty in accessing data. Further, because it only covers executive agencies, the overall access regime is far outweighed by various implementation issues including agencies' reluctance to release documents (Bueza, 2017).

Our interviewees explained that the FOI E.O. has not been helpful because the process of getting data has become more bureaucratic. This has been the overall experience in obtaining data on extrajudicial killings from the Philippine National Police and asset records from the Office of the President. It is recalled as the "golden age" pre-FOI order when Inquirer researchers were able to easily obtain data directly from gatekeepers even as they are just drafting the letter-request (Personal communication, December 11, 2018). Aside from the difficulty in accessing data, government policy also limited the data released, "Pre-FOI, we were able to get raw data; post-FOI, we were given "summarized" statistics" (Personal communication, November 28, 2018).

Still, with or without an FOI law, there are many basic issues concerning data access in the Philippines. For one, most of the data held by agencies are not in open-data format, or dirty, uneven, and unrelated. This is unlike the experience in some Western countries where less work is needed for data to be ready for analysis. The current scenario poses a challenge for journalists, especially for beat reporters, who might not have the time to clean and process data given their daily deadlines. Our informants shared that there had also been instances when agencies released data weeks or months after from the formal request was made, which essentially renders it useless because the news peg is long gone. Some agencies also provide incomplete data, giving only totals instead of the breakdown. 
These are some of the reasons why many data-driven investigations take longer than usual to complete because databases need to be built first. It is not uncommon for reporters to build their own datasets by encoding data straight from hard copies, scraping data, or cleaning and re-encoding dirty data. This is not entirely unique as building own resources is also a mark of good and independent reporting, but this has become more of the norm in the context of data journalism in the Philippines.

The media organizations have also been encountering access limits with the passage of Republic Act No. 10173 or the Data Privacy Act of 2012. Organizations encountered a handful of agencies which denied them data by invoking the Data Privacy Act (Personal communication, January 21,2019$)$. This is a cause for concern as the law is not being used the way the crafters intended it to be implemented. In PCIJ's experience, at least five agencies started withholding information, citing provisions of the new law. The Philippine Securities and Exchange Commission for instance has suspended public access to its Reverse Search Module, a facility that can generate a list of corporate interests of individuals such as shareholdings and board seats in corporations. Because of the Data Privacy Act too, the Bureau of Internal Revenue no longer publishes its annual list of Top 500 Taxpayers online. The Malacañang (Office of the President) Records Office has also decided to redact full address, children's names, and signature in the asset records filed by officials while the Commission on Elections also now redacts donor information in the election statements submitted by candidates. These data were all useful in past PCIJ investigations.

\section{Engaging with multiple publics}


With data journalism expected to facilitate new ways of audience engagement, the news consumption culture and level of data literacy of Filipinos are highly considered by the media agencies when presenting their stories and engaging with their audience.

First, breaking down information to the simplest, most understandable form is crucial, "We have to take into account that (1) a large part of our audience are the masa (masses) and (2) Filipino-language newscasts are our medium" (Personal communication, November 28, 2018). To avoid overwhelming of audiences with numbers implies that translating, editing, and presenting data into easy-to-digest bits of information is essential even as organizations are able to develop complex data and stories.

The second strategy is the use of more photos and infographics to aid the presentation of data (Personal communication, December 11, 2018). This requires research teams to collaborate more actively with the newspaper's Arts Department in conceptualizing an infographic to facilitate comprehensibility without undermining the complexity or depth of the story. This also implies that artists and graphic designers that are digitally literate have become more in demand in newsrooms to support new modes of storytelling.

Our informants also pointed out that the match of the medium and audience need to be accounted for when presenting data in the network's multiple platforms. For example, television is not the best medium for infographics for Filipinos because these would only appear on screen in a matter of seconds and therefore undermines the effort of the data teams. If data tables or graphs need to be shown, these also need to be simple with very limited elements to work well on television given its target audience. Infographics and various kinds of data visualizations are deemed better suited online where readers have more time to interact with the material. News organizations that cater to multiple kinds of audiences, such as ABS-CBN and GMA, make sure 
to adjust the data presentation for specific programs. For example, ABS-CBN has TV Patrol, rendered in Filipino language and catering to a more mass audience in comparison to its cable network ANC, which attracts a more middle to upper class and English speaking audiences. The data-driven features conducted by the group's analytics team are aired on ANC because the content caters more to its audience who are more interested in business-related topics.

Aside from matching the creativity of telling stories to audience needs and assessing the relevant platform of reporting, facilitating audience engagement and feedback to understand their pulse is a crucial consideration. The groups consider social media as a good feedback platform especially when readers provide legitimate and helpful comments, such as whether the report is understandable or whether the work is interpreted correctly.

\section{Data Journalism in the Philippines and Looking Forward}

Data journalism in the Philippines is thriving. Despite some resource limitations, Filipino journalists have come a long way in telling stories through data despite various limitations. It is thus important to situate the practice of data journalism in the country in this context to understand where breakthroughs and barriers lie. The connected narrative of the four news organizations in this study in gathering data from government agencies has been equal parts positive and negative. Denials to state-records requests are part and parcel of ABS-CBN's, GMA's, PCIJ's, and Inquirer's decades' worth of reporting experience. Indeed, getting records has never been consistently quick and easy, but some disclosure mechanisms, even without an FOI law, have helped facilitate data access. More than access per se, what is deemed important in this collective experience is that all four media organizations have learned to adapt with the challenges and have found other ways to obtain and complete datasets or work with what is available. 
All four organizations have in various ways taken advantage of technological developments, i.e., use of applications and programs, to help them better explore the potentials of data journalism such as building web-based data resources, creating interactives and better visualizations, and mapping data to tell better stories. Except for PCIJ which does not run stories daily, ABS-CBN, GMA, and Inquirer have dedicated research staff -- separate from reporters and editors -- whose main focus is data work. This begs the question of whether a research or a data team is a prerequisite for a news organization in order to be able to pursue data-driven outputs. This could well be the answer considering the practical implications tied to producing data stories in a 24-hour news cycle attends to a different target audience, requires a different form of story presentation to address the audience context, and therefore requires significant time and resources. Inevitably, these developments and the future expectations and standards they might create for news reporting quality would inadvertently impact smaller news organizations with relatively limited resources. Apart from building data teams and databases, sustainability emerges as an issue as indicated by some of the discontinued projects of PCIJ (i-Site.ph) and Inquirer (Briefings). Data journalism projects for nonprofits like PCIJ has also relied on donor money, raising another sustainability issue. The current practice and future of data journalism in the Philippines rest on reporters and editors who could benefit from peer-to-peer learning and collaborations as evidenced by the journalistic collaborations at the global level. Reflecting on the findings, the insights below offer some proposed considerations for local journalists to move data journalism forward:

Continue and strengthen efforts to tell data-driven stories and investigations. Data, when gathered, validated, and strategically presented, could reveal new and groundbreaking stories essential in keeping citizens well-informed and people in power in check. News organizations 
must find avenues to sustain this kind of reporting in spite of pressures brought about by the 24hour news cycle.

Improve journalists' data literacy. Diving into data journalism has to be accompanied with efforts that can help journalists become better storytellers of data. News organizations must explore ways to develop an environment in which data-driven reporting becomes an expertise of the many rather than the few and this will imply investing in human resources. Reporters also need to adapt and upgrade their skills to be able to perform multiple roles, when needed, in the digital age.

Support the passage of a robust Freedom of Information Act while strengthening existing disclosure mechanisms. The availability and accessibility problems encountered by journalists in obtaining data are basic but they are important to be addressed in a free press. The passage of an FOI law can help strengthen existing provisions and address weaknesses in various laws concerning document and data access.

Assess and address the problems encountered with the Data Privacy Act. The Data Privacy Act, which was not meant to curb information access, appears to pose unintended problems for journalists who request and use data essential in their reporting. It is crucial to review the principles behind the law and the way it is being implemented.

Consider collaborations. Given the resources needed when embarking on a data journalism project, it might be worth looking into data-driven collaborations between and among news organizations, academe, artists, and civil society. This includes the sharing of databases or collaborating on stories among news organizations and between news organizations and academic researchers. This may help in identifying new ways of reading and interpreting data, 
generating new ways of telling stories, emphasizing crucial issues through cross-referencing of stories, and imagine new ways of engaging audiences.

\section{References}

ABS-CBN Investigative and Research Group. (2016). War on drugs: The unheard voices. Retrieved from https://news.abs-cbn.com/war-on-drugs

Agence France-Presse (2016, May 31). Philippine president-elect says 'corrupt' journalists will be killed. The Guardian. Retrieved from https:/www.theguardian.com/world/2016/may/31/philippine-president-elect-sayscorrupt-journalists-will-be-killed

Appelgren, E. \& Nygren, G. (2014). Data journalism in Sweden. Digital Journalism,2(3), 394405. doi:10.1080/21670811.2014.884344

Berret, C. \& Phillips, C. (2016). Teaching data and computational data journalism. Retrieved from https://journalism.columbia.edu/system/files/content/teaching_data_and_computational_j ournalism.pdf

Borges-Rey, E. (2016). Unravelling data journalism. Journalism Practice, 10(7), 833-843. doi:10.1080/17512786.2016.1159921

Brooten, L. (2011). Media, militarization, and human rights: Comparing media reform in the Philippines and Burma. Communication, Culture \& Critique, 4(3), 229249. doi:10.1111/j.1753-9137.2011.01107.x

Bueza, M. (2017, September 24). Citizen advocates raise issues in FOI rollout. Rappler. Retrieved from https://www.rappler.com/nation/183154-issues-freedom-of-informationimplementation-r2krn-coalition 
Center for Media Freedom and Responsibility (2016, November 16). 'Unheard voices': Humanizing the war on drugs. Retrieved from https://cmfr-phil.org/media-ethicsresponsibility/journalism-review/unheard-voices-humanizing-the-war-on-drugs/

Charbonneaux, J., \& Gkouskous-Giannakou, P. (2015). Data journalism: An investigation practice? Brazilian Journalism Research, 11(2), 244-267.

Coronel, S. (2018, January 17). A fraught time for press freedom in the Philippines. National Public Radio. Retrieved from https://www.npr.org/sections/parallels/2018/01/17/578610243/a-fraught-time-for-pressfreedom-in-the-philippines

Coronel, S., Chua, Y., Rimban, L., Cruz, B. (2004). The rulemakers: How the wealthy and wellborn dominate Congress. Quezon City: Philippine Center for Investigative Journalism.

Fink, K., \& Anderson, C. (2015). Data journalism in the United States: Beyond the "usual suspects”. Journalism Studies, 16(4), 467-481. http://dx.doi.org/10.1080/1461670X.2014.939852

Freedom House. (2017). Freedom of the press 2017. Retrieved from https://freedomhouse.org/report/freedom-press/2017/philippines

Friedrich Ebert Stiftung. (2011). Asian media barometer: Philippines. Retrieved from https://pcij.org/wp-content/uploads/2011/12/Asian-Media-Barometer-The-Philippines2011-Summary.pdf

Howard, A.B. (2014). The art and science of data-driven journalism. Retrieved from https://academiccommons.columbia.edu/doi/10.7916/D8Q531V1

Knight, M. (2015). Data journalism in the UK: A preliminary analysis of form and content. Journal of Media Practice,16(1), 55-72. doi:10.1080/14682753.2015.1015801 
DATA JOURNALISM IN THE PHILIPPINES

Lesage, F., \& Hackett, R. A. (2013). Between objectivity and openness-The mediality of data for journalism. Media and Communication, 1(1), 39-50. doi:10.12924/mac2013.01010039

Oliva, E. (2013). Defining the practice of data journalism in the Philippines. In S. Winkelmann (ed.), Data Journalism in Asia: A Collection of Articles from Members of the Society of Asian Journalists. Retrieved from https://www.kas.de/c/document_library/get_file?uuid=9ecd0cfc-9d30-0967-1d7e04dd9c7c66de\&groupId=252038

Parasie, S. (2014). Data-driven revelation? Digital Journalism,3(3), 364-380. doi:10.1080/21670811.2014.976408

Parasie, S., \& Dagiral, E. (2013). Data driven journalism and the public good: "Computerassisted-reporters" and "programmer-journalists" in Chicago. New Media \& Society, 15(6), 853-871. Retrieved November 11, 2018.

Philippine Center for Investigative Journalism. (2013). The making of MoneyPolitics. Retrieved from http://moneypolitics.pcij.org/\#/about/

Philippine Daily Inquirer (2017, July 16). The kill list. Retrieved from https://newsinfo.inquirer.net/794598/kill-list-drugs-duterte

Reporters Without Borders \& Vera Files. (2016). Media ownership monitor: Philippines. Retrieved from http://philippines.mom-rsf.org/en/

Republic Act No. 53 (1954). An act to exempt the publisher, editor or reporter of any publication from revealing the source of published news or information obtained in confidence. Retrieved from http://www.chanrobles.com/RepublicActNo.53.html\#.XJ6_9usza9Y 
Royal, C. (2012). The journalist as programmer: A case study of The New York Times Interactive News Technology Department. International Symposium on Online Journalism, 2(1), 5-24.

Segel, E., \& Heer, J. (2011). Narrative visualization: Telling stories with data. IEEE Transactions on Visualization and Computer Graphics, 16(6), 1139-1148. doi:10.1109/tvcg.2010.179

Senate of the Philippines (2017, May 15). Bill to protect media practitioners Ok'd. Retrieved from http://www.senate.gov.ph/press_release/2017/0515_prib3.asp

Tandoc, E. C. (2014). Journalism is twerking? How web analytics is changing the process of gatekeeping. New Media \& Society,16(4), 559-575. doi:10.1177/1461444814530541 